\title{
EFFECTS OF AUXINS AND CYTOKININS ON IN VITRO MULTIPLICATION OF BANANA (MUSA SPP.) VARIETY 'W-11’ IN PAKISTAN
}

\author{
S. H. Shah ${ }^{1 *}$, N. Khan ${ }^{1}$, S. Q. Memon ${ }^{1}$, M. Latif ${ }^{2}$, M. A. Zia ${ }^{3}$, A. Muhammad ${ }^{3}$, K. Nasir ${ }^{4}$ and Zafarullah ${ }^{5}$ \\ ${ }^{1}$ Department of Agricultural Sciences, Allama Iqbal Open University, Islamabad, Pakistan; ${ }^{2}$ Office of Research, \\ Innovation and Commercialization (ORIC), Allama Iqbal Open University, Islamabad, Pakistan; ${ }^{3}$ National Institute for \\ Genomics and Advanced Biotechnology (NIGAB), NARC, Islamabad, Pakistan; ${ }^{4}$ Department of Chemistry, Allama \\ Iqbal Open University, Islamabad, Pakistan; ${ }^{5}$ Centre for Biotechnology and Microbiology, University of Swat, Pakistan \\ ${ }^{*}$ Correspondence author e-mail: sabir.hussain@aiou.edu.pk
}

https://doi.org/10.36899/JAPS.2020.1.0012

Published online January 02, 2020

\begin{abstract}
Banana is mostly propagated by conventional method of sucker which is very slow process. Moreover, in vegetative propagation, the plants once infected by pathogen can shift it to many generations and the whole plant population may be infected within few years. In vitro propagation of banana is the best alternative approach that leads to a rapid process of propagation and also the production of disease-free plants. Therefore, the present study was conducted at Plant Tissue Culture Laboratory and Plant Sciences Laboratory, Science Complex, Allama Iqbal Open University, Islamabad, Pakistan during the year 2017. In seven different treatments, Murashige and Skoog basal media was supplemented with different concentrations of BAP and IAA. During this study, the experiments were performed using completely randomized design (CRD) with three replications. Least significant difference (LSD) test was applied to assess the significant differences among means. The results reveal that the highest number of shoots (366.6) was produced after $6^{\text {th }}$ subculture. During this study, the highest proliferation rate (92.22\%) was recorded in $\mathrm{T}_{6}$; MS salts supplemented with BAP $(2.0 \mathrm{mg} / \mathrm{l})$ and IAA $(0.5 \mathrm{mg} / \mathrm{l})$. The minimum number of days (6) for bud initiation was recorded in $\mathrm{T}_{6}$. Similarly, the highest average fresh weight $(14.88 \mathrm{~g})$ was recorded in $\mathrm{T}_{6}$. The highest number of main roots $(9.25 \pm 2.08)$ were recorded in MS basal media supplemented with IAA $(2.0 \mathrm{mg} / \mathrm{l})$ and BAP $(0.5 \mathrm{mg} / \mathrm{l})$. It was followed by MS basal media fortified with IAA $(3.0 \mathrm{mg} / \mathrm{l})$ and BAP $(1.0 \mathrm{mg} / \mathrm{l})$ that gave $7.81 \pm 1.03$ number of shoots. The survival rate $(92 \%)$ was recorded in acclimatization when the plantlets were transferred in plastic pots having peat moss under controlled condition. This optimized protocol would be helpful for mass scale production of high yielding and disease-free banana plants in future.
\end{abstract}

Keywords: Banana Bunchy Top Virus, BAP, IAA, In vitro regeneration, MS basal media.

\section{INTRODUCTION}

Banana (Musa accuminata L.) is used as a supplementary food crop in the most part of the world (Keshari and Pradhan, 2016). Nearly 400 million people of the world use it as a staple food. It is an important income source for many economics and is highly nutritious food (Ali et al., 2011; Hossain et al., 2016). It is an export commodity of Pakistan (http://faostat.fao.org). Although it is highly significant commercial crop but its production is low due to unavailability of reliable and safe planting material (Kumari and Misra, 2016). It is mostly propagated by conventional method of sucker which is very slow process because the rate of sucker multiplication is at the speed of 5-10 per plant per year depending on clone, climate and cultural conditions (Khatun et al., 2017). For a new clone or hybrid, years will be spent when suckers will be ready for propagation to have sufficient planting material for cultivation in acreage. Moreover, in vegetative propagation, the plants once infected by pathogen can shift it to many generations and the whole plant population may be infected within few years. Therefore, the increasing demand of the farmers cannot be fulfilled by the planting material produced by suckers due to several negative impacts like time consuming, poor quality and transmission of diseases (Hussein, 2012). In Pakistan, Banana Bunchy Top Virus (BBTV) attacked on $60 \%$ area under banana cultivation in Sindh during early nineties, and it declined $90 \%$ banana production. This disease was named as banana bunchy top because the infected plants gave bunchy top appearance due to losing of flexibility of leaves that became erect. Due to heavy loss in production by banana bunchy top, the farmers started to cultivate cotton and sugarcane but they could not secure the profit as much as from banana. Efforts were made to obtain the disease-free planting material to re-cultivate banana in these fields. One approach was to import disease-free germplasm, but this approach was not successful because the imported germplasm could not grow well in our local soil and environment (Ali and Mehmood, 2017). The alternate way was to clean and multiply the local germplasm at the highest rate in order to fulfill the needs of the farmers 
(Muhammad et al., 2004). Dwarf Cavendish (Basrai) has been proved to be superior local variety in Sindh climate and released in late $1950 \mathrm{~s}$ for general cultivation. At present, it is a major cultivated variety in the country (Muhammad et al., 2017). But the yield of local dwarf Cavendish is very low (4.4 tons per hectare) as compared to other banana cultivating countries of the world where the average production is $30-35$ tons per hectare.

In vitro propagation of banana is the best alternative approach and it is being used by a large number of countries like Israel, France, Australia, Cuba and Africa etc (Cote et al., 1990; Drew and Smith 1990; Israeli et al., 1995; Vuylsteke, 1998). The efficiency of micro propagation is affected by the rate of multiplication. It has been noticed that the rate of multiplication of banana is genotype dependent (Mendes et al., 1996). A large-scale production of plants by micropropagation technique has many advantages over conventional propagation methods. It is a rapid process of propagation that leads to the production of disease-free plants (Garcia-Gonzales et al., 2010; Jan et al., 2015; Shah et al., 2015). In present era, plant tissue culture technology has achieved a significant importance in mass scale production of plants on industrial basis, disease elimination and plant improvement (Ahmad et al., 2012; Shukla et al., 2017; Ali et al., 2017). A small piece of tissue named as explant can produce thousands of plants in a continuous process in the shortest period of time and space under controlled circumstances throughout the year, irrespective of season and weather (Akin-Idowu et al., 2009). In a recent study, it has been reported that tissue culture technology generates 39\% more yield than that of conventional suckers (Khatun et al., 2017).

Banana (Musa sp.) is a member of family Musaceae and it is considered as one of the essential subsistence crops and next to rice, wheat and maize, it is considered as the $4^{\text {th }}$ most important crop with reference to gross value of agricultural production in the world (CGIAR, 2011). The share of banana is about $22 \%$ in the world's fresh fruit production and ranks second fruit crop after citrus in terms of international trade (FAO, 2012). At present, 150 countries of the world are growing banana and they contribute to their food security and provide income to rural population by producing fruit round the year (Sipen and Davey, 2012). The consistent supply of good quality banana planting material is crucial to meet the rising demand of the banana growers for commercialization (Ngomuo et al., 2014). Banana plants are susceptible by a large number of diseases especially banana bunchy top disease that drastically decreases its productivity (Karule et al., 2016). The conventional clonal method of propagation becomes unable to fulfill the increasing demand of the farmers for disease-free and healthy planting materials of banana. The solution of this problem lies in the production of disease-free banana plants through tissue culture technology that gives vigorous growth of the plants that establish more quickly in the shortest possible time (Uzma et al., 2012; NogueiraLonde et al., 2017). Moreover, tissue culture techniques allow off-season production of banana plants comparable with the plants produced by conventional methods, and they also ensure sustainable production (Ngomuo et al., 2014). Plant growth regulators are critical components of tissue culture media for measuring the pathways of plant cells development (Shah et al., 2013; Shah et al., 2014 a-b). The most commonly used explant sources of banana are the shoot tips obtained from parental pseudostem, suckers, lateral buds and terminal inflorescence apices (Buah et al., 2010). In shoot tip cultures, cytokinins stimulate buds growth and shoot formation, while auxins have marked effects in promoting root induction and development (Ngomuo et al., 2014). It has been found that BAP combined with IAA and NAA reveal the synergism in in vitro multiplication of banana (Sipen and Davey, 2012). The concentration of cytokinin in the rooting medium is much lower than that in the multiplication medium, so that cytokinin/ auxin ratio becomes low which is favorable for root induction (Muhammad et al., 2004). The distribution of planting materials as well as dissemination of information to farmers is a key hurdle for tissue culture technology. Strengthening technical expertise through training of students, technicians and extension specialists will provide the supportive network necessary to the broad-scale adoption of tissue culture technology for industrial growth that will ultimately contribute to the national economy.

The future of banana industry in Pakistan is totally dependent upon in vitro techniques for the quick production of high yielding and disease-free banana plants to replace the infected fields. Therefore, the present research was designed to focus on the improvement of protocols for mass propagation of Chinese cultivar namely $\mathrm{W}-11$ that recently have been introduced by PARC, Islamabad through tissue culture technology. Until now, this tissue cultured cultivar is performing well and getting excellent feedback from the local markets. The need of the hour is that it may be propagated through tissue culture technology at much faster rate in order to replace the conventional planting material. Therefore, the present study was aimed to optimize protocol for in vitro multiplication of banana variety namely $\mathrm{W}-11$. For it, different concentrations of IAA and BAP were assessed for the number of shoots, shoot proliferation, days to bud initiation, fresh mass and root formation. Similarly, three plant growth parameters namely plant height, number of leaves and root weight were compared between primary and secondary hardening.

\section{MATERIALS AND METHODS}


Four weeks old suckers of one exotic germplasm of banana namely "W-11" were acquired from the experimental fields of National Agricultural Research Centre (NARC), Tandojam, Sindh, Pakistan for the establishment of in vitro shoot tip culture. These suckers were taken at Plant Tissue Culture Laboratory and Plant Sciences Laboratory, Science Complex, Allama Iqbal Open University, Islamabad, Pakistan during the year 2017. These suckers were peeled off up to the size of $4 x$ $5 \mathrm{~cm}$ having only one shoot tip. These explants were surface sterilized with $50 \%$ Clorox $(5.75 \% \mathrm{NaOCl})$ along with 4-5 drops of Tween-20 for $15 \mathrm{~min}$. The explants were completely washed with double distilled water to remove the traces of Clorox. The size of final explants was made up to $3-5 \mathrm{~mm}$ in the laminar flow cabinet. The cultures were initiated on MS medium containing 3.0 $\mathrm{mg} / \mathrm{l} \mathrm{BAP}$ and $1.0 \mathrm{mg} / \mathrm{l}$ IAA. In this study, effects of different concentrations of BAP $(12.0,10.0,8.0,6.0,4.0$, 2.0 and $1.0 \mathrm{mg} / \mathrm{l})$ with IAA $(5.0,4.0,3.0,2.0,1.00 .5$ and $0.33 \mathrm{mg} / \mathrm{l})$ were supplemented with MS basal media to optimize the protocol for efficient shoot regeneration of the exotic Musa cultivar namely W-11. After 4 weeks, the cultures were multiplied on MS basal media having different plant growth regulators in different concentrations to achieve maximum multiplication rate (Table 1). After in vitro multiplication, individual shoots were transferred on root induction medium for in vitro root formation. After profuse root formation, the plants were transferred to pots having sterilized homogenous mixture of peat moss and then the plants were covered with polythene sheet to maintain humidity. The hardening of these plants was done in green house for 8 weeks (Khatun et al., 2017).

Statistical analysis: The experiments were laid out following completely randomized design (CRD). In seven different treatments, Murashige and Skoog basal media was supplemented with different concentrations of BAP and IAA. All the values are indicating the mean of three replicates along with the standard deviation after \pm sign. The significant difference was determined by using ANOVA technique at $\mathrm{P} \leq 0.05$. In order to assess the significant differences among means, we applied least significant difference (LSD) test. For this purpose, statistics software namely The Statistix v. 8.1 was used (Analytical Software, 2005). LSD test is demonstrating the significant differences among means at $5 \%$ level of significance.

\section{RESULTS}

Effect of IAA and BAP on number of shoots: Table 2 shows the number of shoots produced by each clone of a banana cv. W-11 after six subcultures along with their mean, variance and coefficient of variance. The data shows that the highest mean number of shoots (366.6) was produced after $6^{\text {th }}$ subculture followed by the mean number of shoots $(223.8$ and 112.8$)$ after $5^{\text {th }}$ and $4^{\text {th }}$ subcultures, respectively. Hence, from the results, it is clear that the highest multiplication rate was noticed in $5^{\text {th }}$ and $6^{\text {th }}$ sub-culturing. Therefore, the cultures should be continued in the next periods in order to main the economic cost of production in addition to saving time, space and other resources.

Effects of BAP and IAA on shoot proliferation, days to bud initiation and fresh mass: Results indicated that various combinations of BAP and IAA significantly $(p \leq$ 0.05 ) affected proliferation rate, days to bud initiation and average fresh mass (Table 3; Table 4). During this study, the highest proliferation rate $(92.22 \%)$ was recorded in $\mathrm{T}_{6}$ : MS salts supplemented with BAP $(2.0 \mathrm{mg} / \mathrm{l})$ and IAA $(0.5 \mathrm{mg} / \mathrm{l})$ followed by $\mathrm{T}_{7}$; MS salts supplemented with BAP $(1.0 \mathrm{mg} / \mathrm{l})$ and IAA $(0.33 \mathrm{mg} / \mathrm{l})$ (Fig. 1). The minimum number of days (6) for bud initiation was recorded in $T_{6}$ followed by $T_{7}$. Similarly, the highest average fresh weight $(14.88 \mathrm{~g})$ was recorded in $\mathrm{T}_{6}$ followed by $T_{7}$ (Table 3). During this study, it was also noticed that the high concentration of BAP $(4.0 \mathrm{mg} / \mathrm{l}$ to $12.0 \mathrm{mg} / \mathrm{l})$ increased the blackening of the explants that resulted in the retardation of shoot multiplication. Similarly, the high concentration of IAA $(1.0 \mathrm{mg} / \mathrm{l}$ to 5.0 $\mathrm{mg} / \mathrm{l})$ retarded the shoot multiplication. Hence, during our study, we noticed that BAP in combination with IAA improved proliferation rate and average fresh mass of the shoots. It means that the synergistic effects of BAP and IAA were noticed on proliferation rate, days to bud initiation and average fresh mass. But the proliferation rate was increased up to a certain limit i.e. $\mathrm{T}_{6}$ and then decreased (Table 3).

Root formation: For full plant recovery, the shoots were shifted to various root induction media after six subcultures (Table 5). From data, it is clear that the higher concentration of IAA and lower concentration of BAP increased the number of roots. The highest number of roots $(9.25 \pm 2.08)$ were recorded in MS basal media supplemented with IAA $(2.0 \mathrm{mg} / \mathrm{l})$ and BAP $(0.5 \mathrm{mg} / \mathrm{l})$. It was followed by MS basal media fortified with IAA (3.0 $\mathrm{mg} / \mathrm{l})$ and BAP $(1.0 \mathrm{mg} / \mathrm{l})$ that gave $7.81 \pm 1.03$ number of shoots (Fig. 1). In this experiment, IAA was found to be the best growth regulator for root initiation with thick and strong roots.

Comparative study during primary and secondary hardening: After efficient roots development, the plantlets were taken out from the culture jars very carefully. The media was washed with tap water to stop the microbial infection. Then, the plantlets were shifted in plastic pots filled with peat moss and were also treated with 1\% IAA solution for more root formation for primary hardening. After one month, the secondary hardening was done for more two months. Three plant 
growth parameters namely plant height, number of leaves and root weight were compared between primary and secondary hardening. It was seen that more plant height $(22.21 \mathrm{~cm})$ was recorded in secondary hardening as compared to plant height $(10.82 \mathrm{~cm})$ obtained in primary hardening. Similarly more number of leaves (9.33) and root weight $(8.97 \mathrm{~g})$ were obtained in secondary hardening compared to number of leaves (9.66) and root weight $(1.91 \mathrm{~g})$ obtained in primary hardening (Table 6). The survival rate $(759 / 825,92 \%)$ was recorded in acclimatization when the plantlets were transferred in plastic pots having peat moss under controlled condition.

Table 1. Different treatments of BAP and IAA used during the present study for shoot multiplication.

\begin{tabular}{cc}
\hline Treatments & BAP + IAA (mg/l) \\
\hline $\mathrm{T}_{1}$ & $12.0+5.0$ \\
$\mathrm{~T}_{2}$ & $10.0+4.0$ \\
$\mathrm{~T}_{3}$ & $8.0+3.0$ \\
$\mathrm{~T}_{4}$ & $6.0+2.0$ \\
$\mathrm{~T}_{5}$ & $4.0+1.0$ \\
$\mathrm{~T}_{6}$ & $2.0+0.5$ \\
$\mathrm{~T}_{7}$ & $1.0+0.33$ \\
\hline
\end{tabular}

Murashige and Skoog basal media was supplemented with different concentrations of BAP and IAA.

Table 2. Number of shoots produced by a banana cv. W-11 after six subcultures.

\begin{tabular}{lcccccc}
\hline \multirow{2}{*}{ Clones } & \multicolumn{5}{c}{ Number of shoots during subcultures } \\
\cline { 2 - 7 } & $\mathbf{1}^{\text {st }}$ & $\mathbf{2}^{\text {nd }}$ & $\mathbf{3}^{\text {rd }}$ & $\mathbf{4}^{\text {th }}$ & $\mathbf{5}^{\text {th }}$ & $\mathbf{6}^{\text {th }}$ \\
\hline 1 & 5 & 9 & 27 & 86 & 125 & 349 \\
2 & 0 & 5 & 18 & 58 & 136 & 215 \\
3 & 3 & 9 & 28 & 76 & 191 & 395 \\
4 & 8 & 16 & 45 & 115 & 398 & 469 \\
5 & 2 & 9 & 32 & 112.8 & 223.8 & 342 \\
Mean & 3.6 & 9.6 & 126.5 & 4645.7 & 12733.7 & 8515.3 \\
Variance & 9.3 & 15.8 & 0.35 & 0.60 & 0.50 & 0.25 \\
C.V. (\%) & 0.85 & 0.41 & & & & 366.6 \\
\hline
\end{tabular}

The results are for the mean of 3 replicates.

Table 3. Effect of different concentrations of BAP and IAA on proliferation rate (\%), days to bud initiation and average fresh mass.

\begin{tabular}{lcccc}
\hline Treatments & No. of explants treated & Proliferation rate (\%) & Days to bud initiation & Average fresh mass (g) \\
\hline $\mathrm{T}_{1}$ & 14 & $29.55^{\mathrm{e}} \pm 5.73$ & $20.00^{\mathrm{a}} \pm 4.58$ & $2.65^{\mathrm{e}} \pm 1.61$ \\
$\mathrm{~T}_{2}$ & 14 & $47.99^{\mathrm{d}} \pm 3.57$ & $18.00^{\mathrm{b}} \pm 5.56$ & $4.12^{\mathrm{de}} \pm 1.97$ \\
$\mathrm{~T}_{3}$ & 14 & $58.83^{\mathrm{c}} \pm 4.28$ & $14.00^{\mathrm{abc}} \pm 4.58$ & $7.33^{\mathrm{cd}} \pm 2.64$ \\
$\mathrm{~T}_{4}$ & 14 & $76.85^{\mathrm{b}} \pm 4.77$ & $17.00^{\mathrm{ab}} \pm 4.58$ & $10.89^{\mathrm{abc}} \pm 4.35$ \\
$\mathrm{~T}_{5}$ & 14 & $79.19^{\mathrm{b}} \pm 8.16$ & $10.00^{\mathrm{bc}} \pm 3.6$ & $9.25^{\mathrm{bc}} \pm 4.45$ \\
$\mathrm{~T}_{6}$ & 14 & $92.22^{\mathrm{a}} \pm 7.93$ & $6.00^{\mathrm{c}} \pm 3.61$ & $14.88^{\mathrm{a}} \pm 5.61$ \\
$\mathrm{~T}_{7}$ & 14 & $85.84^{\mathrm{ab}} \pm 5.79$ & $8.00^{\mathrm{c}} \pm 5.19$ & $12.25^{\mathrm{ab}} \pm 4.2$ \\
\hline
\end{tabular}

Proliferation rate was measured in percentage. Each data is the average of three replicates. Mean values superscripted with different letters show significant differences $(\mathrm{p} \leq 0.05)$ by ANOVA (Statistix v. 8.1). The values after \pm sign demonstrate standard deviation $(\mathrm{n}=$ 3). LSD value for proliferation rate was 9.08 at $p \leq 0.05$; LSD value for days to bud initiation was 8.02 at $p \leq 0.05$; LSD value for average fresh mass was 4.06 at $\mathrm{p} \leq 0.05$.

Table 4. Analysis of Variance (ANOVA) for proliferation rate (\%), days to bud initiation and fresh mass (g).

\begin{tabular}{lcccc}
\hline \multirow{2}{*}{ Source of variation } & \multicolumn{4}{c}{ Mean sum of squares of growth parameters } \\
\cline { 2 - 5 } & DF & Proliferation rate (\%) & Days to bud initiation & Average fresh mass (g) \\
\hline Replication & 2 & 93.49 & 25.00 & 63.65 \\
Treatment & 6 & 1533.45 & 86.71 & 57.65 \\
Error & 12 & 26.09 & 20.33 & 6.31 \\
\hline
\end{tabular}


The results are for the mean of 3 replicates (Significant at $\mathrm{P} \leq 0.05$ ). 5\% $\alpha$ level was assumed for significance.

Table 5. Effect of phytohormones on the number of roots formed eight weeks after culture on root induction media.

\begin{tabular}{ll}
\hline Hormonal combination $(\mathbf{m g} / \mathbf{l})$ & Mean number of roots \\
IAA + BAP & $5.51^{\mathrm{bc}} \pm 1.46$ \\
\hline $1.0+0.33$ & $9.25^{\mathrm{a}} \pm 2.08$ \\
$2.0+0.5$ & $7.81^{\mathrm{ab}} \pm 1.03$ \\
$3.0+1.0$ & $6.15^{\mathrm{b}} \pm 1.24$ \\
$4.0+1.33$ & $3.0^{\mathrm{c}} \pm 1.09$ \\
$5.0+1.5$ & \\
\hline
\end{tabular}

Each data is the average of three replicates.

Mean values superscripted with different letters show significant differences $(\mathrm{p} \leq 0.05)$ by ANOVA (Statistix v. 8.1).

The values after \pm sign demonstrate standard deviation $(n=3)$.

LSD value for mean number of roots was 2.71 at $p \leq 0.05$.

Table 6. Comparative study of plant growth parameters of W-11 during primary and secondary hardening.

\begin{tabular}{lcccccc}
\hline S.No. & \multicolumn{3}{c}{ Primary hardening } & \multicolumn{3}{c}{ Secondary hardening } \\
\cline { 2 - 7 } & Plant height $(\mathbf{c m})$ & No. of leaves & Root weight (g) & Plant height (cm) & No. of leaves & Root weight (g) \\
\hline 1. & 7.61 & 4.33 & 1.28 & 16.25 & 7.33 & 8.67 \\
2. & 8.85 & 5.66 & 1.64 & 19.00 & 9.33 & 7.76 \\
3. & 9.25 & 7.66 & 1.82 & 16.62 & 4.66 & 6.83 \\
4. & 7.35 & 9.66 & 1.19 & 13.85 & 8.66 & 6.09 \\
5. & 10.45 & 8.16 & 1.59 & 20.68 & 7.33 & 8.33 \\
6. & 8.92 & 4.66 & 1.68 & 14.43 & 5.33 & 6.61 \\
7. & 9.77 & 6.00 & 1.91 & 17.00 & 8.00 & 8.04 \\
8. & 10.82 & 7.66 & 1.60 & 22.21 & 9.00 & 8.97 \\
\hline
\end{tabular}

The results are for the mean of 3 replicates.
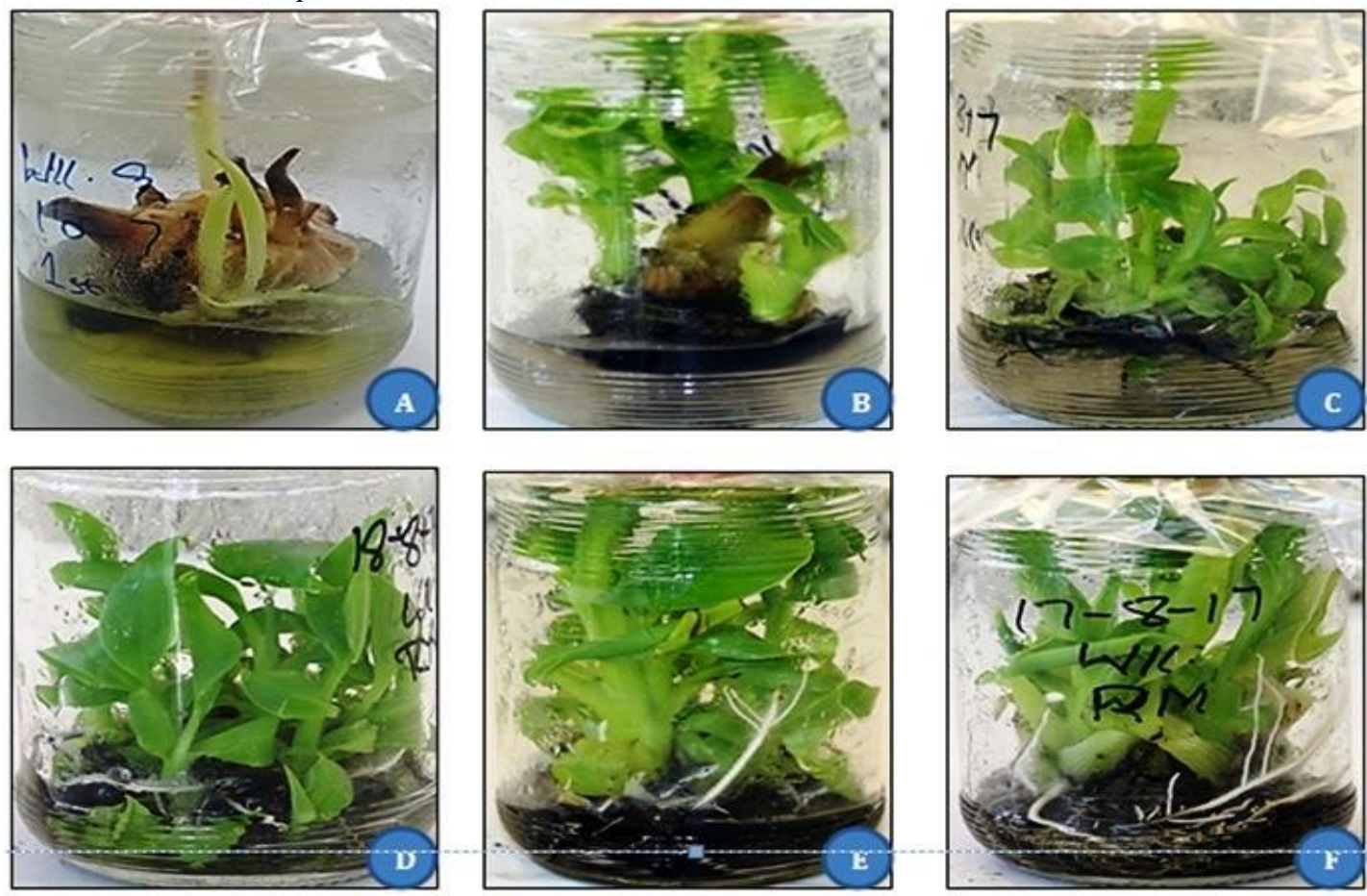

Fig. 1 In vitro multiplication of banana (A) Initiation of shoots from suckers after first culturing (B) Initiation of shoots from suckers after second culturing (C) Initiation of multiple shoots on $\mathrm{T}_{7}$ (MS basal media supplemented with BAP; $1.0 \mathrm{mg} / \mathrm{l}$ and IAA; $0.33 \mathrm{mg} / \mathrm{l})$ (D) Initiation of multiple shoots on $\mathrm{T}_{6}$ (MS basal media supplemented with BAP; $2.0 \mathrm{mg} / \mathrm{l}$ and IAA; $0.5 \mathrm{mg} / \mathrm{l}$ ) (E) Initiation of the number of roots on MS 
basal media supplemented with IAA; $3.0 \mathrm{mg} / \mathrm{l}$ and BAP; $1.0 \mathrm{mg} / \mathrm{l}$ (F) Initiation of the number of roots on MS basal media supplemented with IAA; $2.0 \mathrm{mg} / \mathrm{l}$ and BAP; $0.5 \mathrm{mg} / \mathrm{l}$. DISCUSSION

Banana is an important fruit crop and it is being cultivated on 34,800 -hectare land that gives 154,800 tons production per annum in Pakistan. Around 98\% area under banana cultivation is covered by one Basrai variety (Cavendish dwarf) in Pakistan that produces only 4.4 tons per hectare which is very low as compared to other banana cultivating countries of the world where the average production is $30-35$ tons per hectare. The major cause of low yield of banana in Pakistan is unavailability of healthy planting material. Banana is propagated through suckers that takes a long time and produces a limited number of planting material. Moreover, the propagation by suckers carries various diseases with planting materials. It is the need of the hour that the disease-free planting materials should be produced in the shortest period of time. Therefore, the present project has been designed to produce disease-free banana plants through tissue culture technology all-round the year. The plants produced by this technology are uniform, true to type, pest and disease-free, mature early and give more yields as compared to suckers. The banana plants produced by this project through tissue culture technology will be sent to banana growing areas of province Sindh, Pakistan because the successful growing conditions of banana such as soil and environment have been found to be favorable in those areas, and the farmers also have accessibility to tissue culture plants.

According to Suprasanna et al. (2008), it is very hard to improve banana production due to its sterile and parthenocarpic nature although traditional method of propagation of banana has been a practice in the past. But due to increased human population, the production of banana through traditional means is not sufficient to fulfill the human needs. Because the traditional methods are difficult and time consuming. In vitro micropropagation is an alternative and the best solution of commercial production of disease-free banana plants. It gives quick multiplication of banana in the shortest period of time with restoration of vigor (Suprasanna et al., 2008). In a previous research study by Sipen and Davey (2012) on various Malaysian banana cultivars in which Murashige and Skoog basal media was supplemented with different levels of BAP and IAA. In this study it was concluded that MS basal media fortified with $11.0 \mathrm{mg} / \mathrm{l} \mathrm{BAP}$ and $0.2 \mathrm{mg} / \mathrm{l} \mathrm{IAA}$ produced the highest proliferation rate of nodule like meristems in all the banana cultivars under study. Likewise, the highest plant regeneration was obtained on media containing BAP $(1.0 \mathrm{mg} / \mathrm{l})$ and IAA $(0.2 \mathrm{mg} / \mathrm{l})$.

Different sources of explant and methods have been reported for in vitro techniques of banana propagation (Hamill et al., 1993; Resmi and Nair, 2007;
Shirani et al., 2009). Strosse et al. (2008) reported that meristem tip culture has been found to be the best choice of explant due to its small size although it has high death rate and slow growth at the initial stages. Shoot tip culture method of propagation has been proved to the best method for multiplication of disease and pathogens free plants. Embryos as well as shoot tips cultures are the only methods for organized growth under aseptic conditions. In literature, cytokinins and auxins have been widely used phytohormones that affect elongation and shoot proliferation of banana (Hamide and Pekmezei, 2004; Sipen and Davey, 2012). Among cytokinins, BAP is the most appropriate for in vitro regeneration due to its high stability (Klems et al., 2000; Buah et al., 2000). Likewise, BAP is more efficient in producing shoots as compared to kinetin because of its nature of being noteasily degraded as well as less conjugated amount in plant tissue culture media hence easily accessible for plant tissues (Buah et al., 2000; Rahman et al., 2006). Similarly, BAP plays a central role in shoot formation and multiplication. In a previous research study by Kadota and Niimi (2003), it was reported that MS basal media having $0.25 \mathrm{mg} / \mathrm{l}$ BAP induced the shoot proliferation effectively. In their study, they used MS basal media fortified with BAP $(2.0 \mathrm{mg} / \mathrm{l})$ and NAA $(0.1$ $\mathrm{mg} / \mathrm{l})$ for bud multiplication that resulted 7-8 shoots per explant.

Our findings are in contradictory with the results of a previous research study conducted by Madhulatha et al. (2004) who reported that presence of auxins with cytokinins negatively affected cell enlargement, root formation as well as lateral bud formation. This difference may be due to use of different genotypes of banana. Similar to our findings, Khatun et al. (2017) conducted an in vitro research study on banana variety Sabri and reported that the highest number of shoots (3.4) and in vitro regeneration (84\%) were recorded when BAP alone was used at $5.0 \mathrm{mg} / \mathrm{l}$. They were in argument that BAP and IBA had synergistic effect on in vitro regeneration frequency that produced more response (90\%) compared with BAP alone. Similarly, the combination of BAP $1.5 \mathrm{mg} / \mathrm{l}$ and $1.0 \mathrm{mg} / \mathrm{l} \mathrm{IBA}$ gave the best response for root formation. Previously published literature has described that the best concentration of BAP for shoot proliferation and multiplication in most banana cultivars is $5 \mathrm{mg} / \mathrm{l}$ (Bairu et al., 2006; Venkatachalam et al., 2007). Similarly, Arinaitwe et al. (2000) have shown that the initiation of buds is varying among different cultivars of banana but they found that MS basal media supplemented with $2.0 \mu \mathrm{M}$ IAA and 22.0 $\mu \mathrm{M}$ BAP resulted in the highest number of elongated shoots by sub-culturing. Our findings are in line with Jafari et al. (2011) who reported that the synergistic effect of BAP and IAA produced the best results of 
elongation and proliferation of shoots as compared to BAP alone. Resmi and Nair (2007) conducted a tissue culture study on banana triploid cultivar using flower part as a source of explant and reported that the multiplication rate was high by the combined use of BAP and IAA. The high level of BAP $(44.44 \mu \mathrm{M})$ limited the length and number of shoots of banana cultivar namely Nanjanagudu Rasabale (AAB) ((Venkatachalam et al., 2007). Three main types of auxins including IAA, NAA and IBA are being widely used for the initiation of roots in in vitro culture of banana (Vuylsteke, 1998).

Conclusion: This study indicates that various combinations of BAP and IAA significantly $(\mathrm{p} \leq 0.05)$ affected proliferation rate, days to bud initiation and average fresh mass. The highest proliferation rate $(92.85 \%)$ was recorded in $\mathrm{T}_{6}$; MS salts supplemented with BAP $(2.0 \mathrm{mg} / \mathrm{l})$ and IAA $(0.5 \mathrm{mg} / \mathrm{l})$. During this study, it was also noticed that the high concentration of BAP $(4.0 \mathrm{mg} / \mathrm{l}$ to $12.0 \mathrm{mg} / \mathrm{l})$ increased the blackening of the explants that resulted in the retardation of shoot multiplication. Similarly, the high concentration of IAA $(1.0 \mathrm{mg} / \mathrm{l}$ to $5.0 \mathrm{mg} / \mathrm{l})$ retarded the shoot multiplication. During our study, we noticed that the synergistic effects of BAP and IAA improved the proliferation rate and average fresh mass of the shoots. It is also clear from our findings that the higher concentration of IAA than that of BAP increased the number of roots. The highest number of roots $(9.25 \pm 0.26)$ were recorded in MS basal media supplemented with IAA $(2.0 \mathrm{mg} / \mathrm{l})$ and BAP $(0.5 \mathrm{mg} / \mathrm{l})$. IAA was found to be the best growth regulator for root initiation with thick and strong roots.

Acknowledgements: The authors are highly thankful to Higher Education Commission, Islamabad-Pakistan for providing funding under the research grant no. 21-659 SRGP/R\&D/HEC/2015.

Conflict of Interest: The authors declare that they have no conflict of interest.

\section{REFERENCES}

Ahmad, M. Z., I. Hussain, S. Roomi, M. A. Zia, M. S. Zaman, Z. Abbas, and S. H. Shah (2012). In vitro response of cytokinin and auxin to multiple shoot regeneration in Solanum tuberosum L. American-Eurasian J. Agric. \& Environ. Sci. 12(11): 1522-1526.

Akin-Idowu, P. E., D. O. Ibitoye, and O. T. Ademoyegun (2009). Tissue culture as a plant production technique for horticultural crops. Afr. J. Biotechnol. 8(16): 3782-3788.

Ali, A., A. Sajid, N. H. Naveed, A. Majid, A. Saleem, U. A. Khan, F. I. Jafery, and S. Naz (2011). Initiation, proliferation and development of micro-propagation system for mass scale production of banana through meristem culture. Afr. J. Biotechnol. 10(70): 15731-15738.

Ali, S., S. Khan, S. H. Shah, A. Iqbal, M. A. Zia, and G. M. Ali (2017). Development of efficient regeneration and genetic transformation systems in local cultivars of chickpea (Cicer arietinum L.). J. Anim. Plant Sci. 27(6): 2025-2034.

Ali, S., and S. Mehmood (2017). Micro propagation of cv. Basrai (Banana) using growth hormones. J. Hortic. 4(1): 195-196.

Analytical Software. (2005). Statistix version 8.1: User's manual. Analytical Software, Tallahassee, Florida.

Arinaitwe, G., P. R. Rubaihayo, and M. J. S. Magambo (2000). Proliferation rate effects of cytokinins on banana (Musa spp.) cultivars. Sci. Hortic. 86: 13-21.

Bairu, M. W., C. W. Fennell, and J. Van Staden (2006). The effect of plant growth regulators on somaclonal variation in Cavendish banana (Musa AAA cv. 'Zelig'). Sci. Hortic. 108: 347351.

Buah, J. N., E. Danso, K. J. Taah, E. A. Abole, E. A. Bediako, J. Asiedu, and R. Baidoo (2010). The effects of different concentrations cytokinins on the in vitro multiplication of plantain (Musa sp.). Biotechnol. 9(3): 343-347.

Buah, J. N., Y. Kawamitsu, S. Yonemori, and S. Murayama (2000). Field performance of in vitro-propagated and sucker-derived plants of banana (Musa spp.). Plant Prod. Sci. 3: 124-128.

CGIAR. (2011). Research and impact: Area of researchbanana

Available: www.cigar.org/impact/research/Banana.html (Accessed 22/09/2011).

Cote, F., D. Alvard, R. Domergue, L. N. Mastache, and C. Teisson (1990). In vitro micropropagation of banana. Fruits (special): 112-118.

Drew, R. A., and M. K. Smith (1990). Field evaluation of tissue cultured bananas in southeastern Queensland. Aust. J. Exp. Agr. 30: 569-574.

FAO. (2012). Statistics web site. Available: http://www.fao.org.2010 (Accessed on 04/10/2012).

Garcia-Gonzales, R., K. Quiroz, B. Carrasco, and P. Caligari (2010). Plant tissue culture: Current status, opportunities and challenges. Cienc. Investig. Agrar. 37(3): 5-30.

Hamide, G., and M. Pekmezci (2004). In vitro propagation of some new banana types (Musa sp.). Turk. J. Agric. 28: 355-361.

Hamill, S. D., S. L. Sharrock, and M. K. Smith (1993). Comparison of decontamination methods used in initiation of banana tissue cultures from fieldcollected suckers. Plant Cell Tiss. Org. 33: $343-$ 346. 
Hossain, M. A., M. H. Rubelb, K. M. Nasiruddinc, and F. Z. Evamonia (2016). Influence of BAP and NAA on in vitro plantlet regeneration of local and exotic banana cultivars. J. Biosci. Agric. Res. 6(2): 553-564.

Hussein, N. (2012). Effects of nutrient media constituents on growth and development of banana (Musa spp.) shoot tips cultured in vitro. Afr. J. Biotechnol. 11: 9001-9006.

Israeli, Y., E. Lahav, and O. Reuveni (1995). In vitro culture of bananas. Fruits. 43: 219-223.

Jafari, N., R. Y. Othman, and N. Khalid (2011). Effect of benzylaminopurine (BAP) pulsing on in vitro shoot multiplication of Musa acuminata (banana) cv. Berangan. Afr. J. Biotechnol. 10(13): 2446-2450.

Jan, S. A., S. H. Shah, S. Ali, and G. M. Ali (2015). The effect of plant growth regulators on the callus induction and somatic embryogenesis of hybrid tomato. Pakistan J. Bot. 47(5): 1671-1677.

Kadota, M., and Y. Niimi (2003). Effects of cytokinin types and their concentrations on shoot proliferation and hyperhydrocity in vitro pear cultivar shoots. Plant Cell Tiss. Org. 72: 261265.

Karule, P., V. Dalvi, A. Kadu, R. Chaudhari, V. R. Subramaniam, and A. B. Patil (2016). A commercial micropropagation protocol forvirupakshi (AAB) banana via apical meristem. Afr. J. Biotechnol. 15(11): 401-407.

Keshari, B., and B. Pradhan (2016). Effects of cytokinins and auxins on micropropagation of Musa spp. cv. Yangambi. Int. J. Env. Agric. Res. 2(5): 156158.

Khatun, F., M. E. Hoque, H. Huq, M. Adil, K. AshrafUz-Zaman, and M. H. Rabin (2017). Effect of BAP and IBA on in vitro regeneration of local banana variety of Sabri. Biotechnol. J. Int. 18(1): 1-10.

Klems, M., J. Balla, I. Machackova, J. Eder, and S. Prochazka (2000). The uptake and Metabolism of Benzylaminopurine in tobacco (Nicotiana tabacum L.) and Cucumber (Cucumis sativus L.) explants. Plant Growth Regul. 31: 135-142.

Kumari, N., and P. Misra (2016). Mass in-vitro micro propagation of banana (Musa sp.). Int. J. Plant Protect. 9(1): 204-210.

Madhulatha, P., M. Anbalagan, S. Jayachandran, and N. Sakthivel (2004). Influence of liquid pulse treatment with growth regulators on in vitro propagation of banana (Musa spp. AAA). Plant Cell. Tiss. Org. 76: 189-192.

Mendes, B. M. J., F. J. Mendes, A. T. Neto, C. G. B. Demetrio, and O. R. Puske (1996). Efficacy of banana plantlet production by micropropagation. Pesqui. Agropecu. Bras. 31: 863-867.
Muhammad, A., I. Hussain, K. A. Khanzada, L. Kumar, M. Ali, T. Yasmin, and M. Z. Hyder (2017). Molecular characterization of FusariumoxysporumF. SP. Cubense (Foc) tropical race 4 causing Panama disease in Cavendish banana in Pakistan. Pakistan J. Agr. Sci. 54(1): 1-8.

Muhammad, A., I. Hussain, S. M. S. Naqvi, and H. Rashid (2004). Banana plantlet production through tissue culture. Pakistan J. Bot. 36(3): 617-620.

Ngomuo, M., E. Mneney, and P. A. Ndakidemi (2014). The in vitro propagation techniques for producing banana using shoot tip cultures. Am. J. Plant Sci. 5: 1614-1622.

NogueiraLonde, L. C., W. A. Vendrame, A. B. De Oliveira, M. Sanaey, and A. M. Costa (2017). Phloroglucinol is effective for in vitro growth and multiplication of Musa accuminata Cv. Grand Naine shoots and roots. J. Adv. Biol. Biotechnol. 13(2): 1-8.

Rahman, M. Z., M. G. Sharoar, M. N. Matin, M. H. Rahman, M. M. Rahman, and M. R. Islam, (2006). High frequency plant regeneration of a dessert banana cv. Mehersagar for commercial exploitation. Biotechnol. 5(3): 296-300.

Resmi, L., and A. S. Nair (2007). Plantlet production from the male inflorescence tips of Musa acuminata cultivars from South India. Plant Cell. Tiss. Org. 88: 333-338.

Shah, S.H., S. Ali, and G. M. Ali (2013). A novel approach for rapid in vitro morphogenesis in tomato (Solanum lycopersicum Mill.) with the application of cobalt chloride. Eur. Acad. Res. 1(9): 2702-2721.

Shah, S. H., S. Ali, S. A. Jan, and G. M. Ali (2014a). Assessment of carbon sources on in vitro shoot regeneration in tomato. Pakistan J. Agr. Sci. 51(1): 197-207.

Shah, S. H., S. Ali, S. A. Jan, J. U. Din, and G. M. Ali (2014b). Assessment of silver nitrate on callus induction and in vitro shoot regeneration in tomato (Solanum lycopersicum Mill.). Pakistan J. Bot. 46(6): 2163-2172.

Shah, S. H., S. Ali, S. A. Jan, J. U. Din, and G. M. Ali (2015). Callus induction, in vitro shoot regeneration and hairy root formation by the assessment of various plant growth regulators in tomato (Solanum lycopersicum Mill.). The J. Anim. Plant Sci. 25(2): 528-538.

Shirani, S., F. Mahdavi, and M. Maziah (2009). Morphological abnormality among regenerated shoots of banana and plantain (Musa spp.) after in vitro multiplication with TDZ and BAP from excised shoot tips. Afr. J. Biotechnol. 8(21): 5755-5761. 
Shukla, M. R., A. S. Singh, K. Piunno, P. K. Saxena, and A. M. P. Jones (2017). Application of 3D printing to prototype and develop novel plant tissue culture systems. Plant Methods. 13: 2-10.

Sipen, P., and M. R. Davey (2012). Effects of $\mathrm{N}^{6}$ benzylaminopurine and indole acetic acid on in vitro shoot multiplication, nodule-like meristem proliferation and plant regeneration of Malaysian bananas (Musa spp.). Trop. Life Sci. Res. 23(2): 67-80.

Steel, R. G. D., J. H. Torrie, and D. A. Dickey (1997). Principles and procedures of statistics: A biological approach. $3^{\text {rd }}$ Edition: McGraw Hill Book Co. Inc. , New York

Strosse, H., E. Andre, L. Sagi, R. Swennen, and B. Panis (2008). Adventitious shoot formation is not inherent to micropropagation of banana as it is in maize. Plant Cell Tiss. Org. 95: 321-332.

Suprasanna, P., M. Sidha, and T. R. Ganapathi (2008). Characterization of radiation induced and tissue culture derived dwarf types in banana by using a SCAR marker. Aust. J. Crop Sci. 1(2): 47-52.

Uzma, M. R. Khan, A. Muhammad, I. Hussain, S. H. Shah, T. Kumar, S. Inam, M. Zubair, H. U. Rehman, A. Sher, N. Rehman, S. Ahmed, and G. M. Ali (2012). Rapid in vitro multiplication of sugarcane elite genotypes and detection of sugarcane mosaic virus through two steps RTPCR. Int. J. Agric. Biol. 14(6): 870-878.

Venkatachalam, L., R. V. Sreedhar, and N. Bhagyalakshmi (2007). Micropropagation in banana using high levels of cytokinins does not involve any genetic changes as revealed by RAPD and ISSR markers. Plant Growth Regul. 51: 192-205.

Vuylsteke, D. R. (1998). Shoot-tip culture for the propagation, conservation, and distribution of Musa germplasm. Ibadan, Nigeria: International Institute of Tropical Agriculture. 